\title{
Analysis of the Disruptive Technologies of Anti-Terrorist Operations
}

\author{
Zhibo Nie ${ }^{1,2, *}$, Minle Wang ${ }^{1}$, Jian Feng ${ }^{2}$, Hang Tian ${ }^{2}$ \\ ${ }^{1} X i^{\prime} a n$ Hi Tech Research Institute, Xi'an, China \\ ${ }^{2}$ Engineering University of Xi'an, Xi'an, China \\ *corresponding author email: nerpenmath@yeah.net
}

Keywords: Disruptive Technology, Demand, Anti-Terrorism

Abstract: The development and applications of disruptive technology is introduced in this paper. The effect of subversive terrorist attack mode is investigated, the demand for disruptive technology of anti-terrorist forces is discussed as such technology is applied to the efforts against terrorism. Besides, the development orientations of the disruptive technologies applied in anti-terrorism and worth-noting issues in future anti-terrorist operations are pointed out.

\section{Introduction}

Disruptive technology is a technology that can change the rules of the game, first put forward by Professor Clayton M. Christensen from Harvard Business School in his book, Disruptive Technologies: Catching the Wave[1],The aim of disruptive technology is "to replace" the mainstream technology in a certain field, In the field of national defense and military affairs, which refers to shattering existing cognitive patterns or technological systems in national defense and military, realizing exponential betterment of the combat effectiveness of weapons, forming new unconventional or asymmetric combat capabilities, and generating new modes of operation or new principle, new mechanism and new concept that even reshapes the face of war, the U.S. Department of Defense defines it as "a technology to quickly break the balance of forces between rivals"[2].The disruptive technology as show in Fig.1.

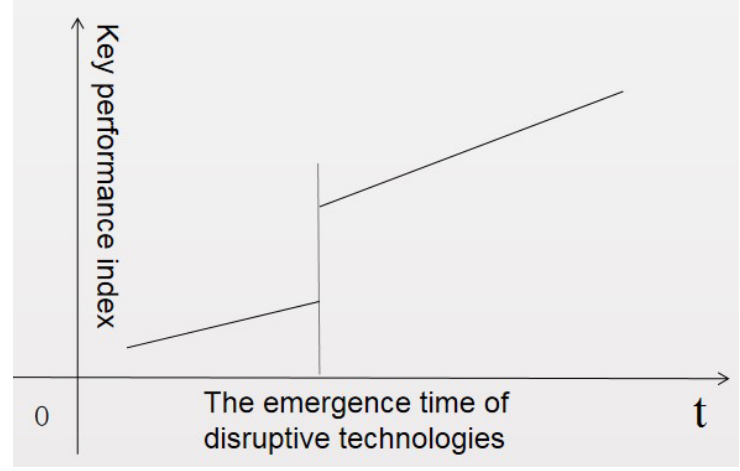

Fig 1 Schematics of disruptive technology 
In China, violent and terrorist events caused by the "Three evil force" have been the cancer that poses threats against regional and social stability [3]. For the force against terrorism, applied the research achievements of disruptive technologies to anti-terrorist operations and good effects that are conducive to maintaining a prolonged political stability is therefore anticipated.

\section{Technical Analysis of Disruptive Technology Terrorist Attacks}

With the emergence of disruptive technology, terrorists are gradually pursuing disruptive terrorist ideas and weapons with asymmetric warfare effectiveness, and combining the two.

\subsection{Conventional measure and strategies of terrorist attacks}

Common forms of terrorist attacks include explosion, hacking, vehicle collision, hijacking, hostage-taking, assassination, kidnapping and extortion, suicide bombing, etc. For these forms of terrorist attacks, the anti-terrorist forces have corresponding counter-terrorism experience and mature methods of warfare, so the social impact of such terrorist attacks is limited.

\subsection{Terrorist attacks with disruptive effects}

First of all, from historical experience, Al-Qaida disruptively used the collision of civil aviation airliners in September 11[4],From the result analysis, it was a disruptive terrorist attack which integrated hijacking, hostage-taking, suicide terrorist attacks and explosions, which produced disruptive terrorist attacks. In November 2015, the terrorist attacks made by ISIS in Paris utilized the comprehensive use of such terrorist methods as shooting, collision [5], explosion and multi-point co-occurrence, and produced disruptive attack effects.

Secondly, the application of some conventional operational ideas to terrorist attacks can also produce disruptive terrorist effects. In some countries and regions of the Middle East, ISIS used the method of formed armed attack to control a large number of cities, and carried out the policy of terrorist social management and the terrorist attacks of Chechnya armed elements on Grozny and Moscow Grand Theatre, which all produced disruptive effects [6-7]. In Syria, ISIS and other terrorist organizations used civilian UAVs to hang mortar shells to attack US military patrols, which directly offset the defensive effect of US lightning-proof vehicles. Similar tactics were also used by ISIS to attack Russian military bases in Syria, resulting in a large consumption of Russian airborne weapons.

Thirdly, in the disruptive effect, the advantage of scale may replace the advantage of weapons and equipment. This concept of combat is also absorbed by terrorists for terrorist attacks. The 2008 Mumbai terrorist attack is the comprehensive application of this disruptive terrorist idea, Although terrorists are far less powerful than the anti-terrorism force, However, the use of multi-point co-attack attacks in Mumbai led to a large number of casualties [8].

\subsection{Possible disruptive terrorist attacks in the future}

Based on historical experience, it is possible for terrorists to launch subversive terrorist attacks in finance, transportation, national economy and people's livelihood by using existing technology and weapons, or their newly developed high-tech terrorist equipment, combined with the concept of disruptive terrorist attacks. 


\section{Demand for Disruptive Technologies that Improve the Performance of Anti-Terrorism}

The features of anti-terrorist operations are different from those of the operations of other armed forces. A conclusion can be drawn that there is a demand for disruptive technologies in terms of intelligence support, weapons, logistics support, operations features and features of opponents in consideration of the characteristics of how domestic terrorists make terrorist attacks at present and in combination of the analysis of the factors that led to current violent and terrorist events in China.

\subsection{Big data analysis on anti-terrorism}

In the age of information, there is a growing number of risks in national security. The uncertainties in situations control, outcome forecast and backup planning in national security are increasing. Big data is helpful to reduce the uncertainty in the process by making use of its advantages in information collection, storage and analysis. Also, big data analysis is gradually replacing conventional surveillance approaches and becoming an important source of information for high levels to make decisions. The sources of data are varied which expanded the accessible domains where military intelligence is collected. We may say that "big data is the virtual chiefs of staff where decision-making advantages are obtained in the age of intelligence [9].”

1) At present, terrorist attacks are deeply intertwined with the international situations and economic, cultural, social and religious factors.

The operations against terrorism, whether domestic or overseas, are now united. The trends of planning attacks overseas, communicating online and jointly executing domestically are becoming quite obvious. Therefore, big data analysis is able to unearth effective information and intelligence related to extremism and terrorism out of the massive data in online chat rooms, website data flow and many other channels, so that the spreading of terrorism and communication paths among terrorists can be isolated. The reasonable use of such intelligence may effectively intercept the spreading of extremism, cut off the communications and contain the occurrence of violent and terrorist events. Effective countermeasure information can also be dug out from data history for those attacks already occurred, launching strikes down upon relevant terrorists.

2) Any terrorist attack is in need of strong financial support from its planning to executing. The sources of fund, by far, come from personal donations of those who support terrorism, anti-China forces overseas and illegal income of terrorist organizations in addition to kidnap and ransom. With the big data analysis of economic activities, we may better locate and cut off their financial sources, which are very much conducive for anti-terrorism.

3) Terrorists are often somewhat related to the targets they select. To implement a terrorist event, it requires a certain amount of capable terrorists, and the targets selected are usually of high values and social influence. Therefore, the big data analysis of the information of high-value targets and relevant personnel is helpful to identify the relations between potential suspects and targets, so that early warning can be more accurate.

\subsection{Artificial intelligence on anti-terrorism}

Macroscopically speaking, how to cut off the spreading of extremism has always been the key area of the studies on anti-terrorism. Microscopically speaking, intelligent weapons and equipment serve as the physical foundation for better anti-terrorist combat effectiveness. To realize the overall demand for anti-terrorism, whether macroscopic or microscopic, a myriad of human resources are required. The use of AI can adapt to the needs of operations quickly, accurately and efficiently, freeing human resources from onerous information identification works. The integration of AI and weapon systems may accomplish missions such as analysis, surveillance, search, identification, 
aiming and hitting targets either automatically or semi-automatically. The introduction of AI will achieve a disruptive effect in the field of anti-terrorism.

1) How to cut off the spreading of extremism is the key question in the anti-terrorism efforts of different countries. However, it is extremely difficult to organize international cooperation due to different philosophies and standards in those countries. Also, the spreading of terrorism and terrorist ideas has been extensive around the world because of the double standard in certain countries.

At present, terrorism-related videos and audios in overseas websites and contained in other media forms still manage to enter China via multiple channels. The websites of overseas anti-China forces are using several methods to "cross the barrier" in order to smuggle these videos and audios into China. This information is providing great support to terrorists and posing a grave threat against our national security.

The efficiency of AI is significantly higher than technicians in terms of the authentication of terrorism-related videos and audios, identification of extremist statements and VPN software. Therefore, the application of AI in anti-terrorism will build an anti-terrorist firewall for our country.

2) Microscopically, intelligent anti-terrorist weapons and equipment will greatly improve the anti-terrorist performance. So far, intelligent weapons and equipment keep emerging endlessly in anti-terrorism. The Big Dog robot, developed by the U.S Armed Forces, has already reflected great advantages in battlefield support. Besides, the next generation of intelligent unmanned combat platform is under intense development process. The surveillance-strike aerial combat platforms of the US and Russia have already realized battlefield application, and a number of terrorists ringleaders such as Osama Bin Laden and Dudayev have been neutralized. Intelligent transport and combat robots, like the Big Dog [10], are urgently needed in anti-terrorism, as well as security check and surveillance-strike smart weapon platforms. Therefore, anti-terrorism would achieve qualitative leap forward if such intelligent weapon systems can be applied. The 9.18 Baicheng terrorist attacks in China, in which terrorists fled to the depths of the Tianshan Mountains, caused tremendous difficulties to the logistical supply and reconnaissance of the anti-terrorism forces. Therefore, some intelligent transportation and combat robots like the Big Dog can enter the intelligent weapon platform for security inspection and investigation and attack. If used in the field of anti-terrorism, they will produce disruptive anti-terrorism effects.

\subsection{Disruptive principles of operations on anti-terrorism}

Military disruptive technology highlights the capability of forming unconventional or asymmetric combat capabilities, which not only includes breakthroughs in high-end technologies, but more importantly, including those middle-end or even low-end innovative technologies that are somewhat disruptive in a certain range.

1) Innovating some simple combat ideas and low-end technologies may generate disruptive effects in anti-terrorist operations. During the Gulf War, the U.S Armed Forces placed six battlefield preset ships, fully loaded with weapons, in their base in the Indian Ocean. Such disruptive idea of presetting weapons in battlefield achieved deploying one heavy-armored brigade and becoming combat effective and quickly responsive to targets within three days. Similarly, we may also preset a certain quantity of weapons and equipment in hot zones when we launch overseas anti-terrorist operations, enabling quick response.

In the meanwhile, if standard weapons for combat in certain regions can be preset in hot zones in China, by borrowing such disruptive equipment storage idea from the U.S, and wheel war is adopted, so that not only the war itself trains the troops, but it also betters our anti-terrorist forces in terms of combat effectiveness and rapid response, which is, too, conducive to higher use rate of weapons and lower stability safeguard cost. 
2) Compellingly asymmetric high-end technologies known as "suppressing the low with high" is often sought after in anti-terrorism. But some middle and low-end tactic innovations are able to generate disruptive effects on anti-terrorist war or the implementation of terrorist attacks. In Iraq, the idea of disruptive innovation is also applied by terrorists. Tactically, IEDs are extensively used, in spite of its low technological content, it creates considerable casualties of American soldiers as well as other collateral impacts spiritually and psychologically, even affected the anti-terrorist philosophy of the United States. Boko Haram abducted children and had them brainwashed to sacrifice themselves as suicide bombers, these tactical innovations disrupted the ideas in anti-terrorist war.

These disruptive terrorist attacks can be spread to China via different channels. Therefore, corresponding training against these attacks should be organized in advance.

3) Other applicable disruptive technologies on anti-terrorism

Most of the 12 disruptive technologies issued by MGI in 2013 can be disruptively effectively in military, and they can also be used in anti-terrorism [11].In addition, many other technologies, which were not included in the MGI list for the moment, may bring about disruptive effects in anti-terrorism. Also, tactical innovation is capable of being disruptive in anti-terrorism as well.

\section{Prospect of the Studies on the Disruptive Technology of Anti-Terrorist Operations}

Disruptive technology is applicable to every single aspect of anti-terrorist operations. Highly efficient studies and applications of disruptive technology will greatly improve the performance of anti-terrorism.

Even though the Armed Police Forces, at present, still have to face the great asymmetric advantages terrorists have, the application of disruptive technology, used by terrorists, will change the offense-defense balance of terrorism \& anti-terrorism system, and the quality advantage of anti-terrorist forces will be offset.

Therefore, greater efforts shall be devoted in the studies of basic sciences, according to the features of disruptive technology in future studies on anti-terrorist operations, and more matured disruptive technologies with anti-terrorist shall be applied to lower the cost and achieve social stability. Meanwhile, anti-terrorist forces shall actively innovate tactics based on the trends of disruptive technology, and avoid situations where they are rendered incapable of dealing with those terrorist events made with disruptive technology.

\section{References}

[1] Christensen C M. Disruptive technologies: catching the next wave [M]. Harvard Business Review, 1995

[2] Creating breakthrough technologies for national security defence advanced research projects agency[R].DARPA. 2016

[3] Yue L, Wu Y. Research on the Impact of Crisis Events on Urban Development-A Case Study of Kunming Railway Station Terrorist Attack[M].Proceedings of the 20th International Symposium on Advancement of Construction Management and Real Estate. 2017.

[4] Schlenger W E. Psychological Sequelae of the September 11 Terrorist Attacks in New York City [J]. N Engl J Med, 2002, 346(13):982-987.

[5] Mahat-Shamir M, Hoffman Y, Pitcho-Prelorentzos S, et al. Truck attack: Fear of ISIS and reminder of truck attacks in Europe as associated with psychological distress and PTSD symptoms [J]. Psychiatry Research, 2018, 267:306-312.

[6] Nettelfield L J. Terror in Chechnya: Russia and the Tragedy of Civilians in War (review) [J]. Human Rights Quarterly, 2011, 33(3):886-890.

[7] Londre F H. Anton Chekhov at the Moscow Art Theatre: Archive Illustrations of the Original Productions (review)

[J]. Theatre Journal, 2006, 58(1):161-162.

[8] Bhattacharjya M. Another kind of terror [J]. Texas Dental Journal, 2016, 94(1):7-8.

[9] Li Bingyan. Disruptive Technology and War-Winning Mechanism [N]. PLA Daily, 2014 -5 -6 (006)

[10] Ding L. Key Technology Analysis of Big Dog Quadruped Robot [J]. Journal of Mechanical Engineering, 2015, 
51(7).

[11] Jacques Bughin. Jacques Bughin. Twelve Future-Shaping Disruptive Technologies [R], Silicon Valley, 2013(14): 24-27. 